\title{
Urbanização de favelas na Região do ABC no âmbito do Programa de Aceleração do Crescimento-Urbanização de Assentamentos Precários
}

\author{
Slum upgrading in the ABC Region in the context \\ of Programa de Aceleração do Crescimento- \\ -Urbanização de Assentamentos Precários
}

Rosana Denaldi

Ricardo Moretti

Claudia Paiva

Fernando Nogueira

Juliana Petrarolli

\section{Resumo}

Este trabalho trata das intervenções em favelas localizadas na Região do $A B C$ e financiadas no âmbito do Programa de Aceleração do Crescimento - Urbanização de Assentamentos Precários (PAC-UAP). ${ }^{1}$ Esse programa canaliza recursos para ações de urbanização de 49 assentamentos precários do tipo favela ou loteamentos irregulares nessa região. Observa-se que é baixa a execução dos contratos de financiamento e repasse. A caracterização dos assentamentos e das intervenções fornece um panorama geral da execução do programa e possibilita identificar seus entraves. Conclui-se que, para compreender os baixos índices de execução das obras de urbanização de favelas será importante entender a característica desses territórios, natureza das intervenções, regulamentação e operacionalização do programa e as limitações institucionais dos governos municipais.

Palavras-chave: favela; assentamentos precários; urbanização de favelas; região do $A B C$.

\begin{abstract}
This paper analyzes interventions in slums located in the $A B C$ Region (State of São Paulo, Brazil) that have been financed in the context of Programa de Aceleração do Crescimento - Urbanização de Assentamentos Precários (PAC-UAP). Through this program, financial resources aimed at the upgrading of 49 precarious settlements (slums) are allocated to this region. The research shows evidence of low efficiency in the implementation of projects. Our characterization of the settlements and interventions provides a general panorama of the program's implementation and its bottlenecks. It is concluded that, to understand the lack of efficiency in slum upgrading, it is important to understand the characteristics of these territories, the nature of interventions, the regulation and operationalization of the program, and the institutional limitations of municipal governments.
\end{abstract}

Keywords: slums; precarious settlements; slum upgrading; $A B C$ Region. 


\section{Introdução}

O lançamento do Programa de Aceleração do Crescimento - Urbanização de Assentamentos Precários (PAC-UAP) ${ }^{2}$ marcou um novo momento da política de urbanização de favelas no país: o governo federal, pela primeira vez, aplica recursos volumosos nesse tipo de intervenção. Vale ressaltar que, até início da primeira década de 2000, o principal protagonista nessa área era o município e os valores investidos pelo governo federal em programas de urbanização de favelas até então foram irrisórios (Denaldi, 2004).

Historicamente, a provisão de moradias para população de menor renda não se deu pela via do mercado formal ou do Estado. A favela foi uma das alternativas habitacionais encontradas pela população que não conseguiu acessar o mercado formal de moradias.

Nos países periféricos, como o Brasil, os gastos com a moradia não foram incorporados aos salários pagos pela indústria e nem assumidos pelo Estado. Maricato (1996) aponta que a "favelização" das cidades está relacionada com as características excludentes do mercado imobiliário formal e com a "urbanização com baixos salários". Para a autora, o Estado fez-se presente no espaço da acumulação, mas se ausentou do espaço da miséria. 0 crescimento das favelas é, portanto, resultado também da ausência e conivência do Estado.

A erradicação foi a alternativa mais defendida até a década de 1960. A partir da década de 1970, quando o Estado interveio, admitindo a urbanização das favelas, ele o fez valendo-se de "programas alternativos" de pequena abrangência e desligados do eixo estrutural da política habitacional e das estruturas institucionais. 0 primeiro programa federal que permitiu a intervenção em favelas foi o Promorar, instituído no período de existência do Banco Nacional de Habitação (BNH) e que também pode ser considerado como um programa alternativo.

A ação governamental restringiu-se à produção de novas unidades habitacionais e a intervenção do tipo "urbanização de favelas" entrou para agenda federal apenas na década de 1990. No governo de Itamar Franco (1992 a 1994) foi formulado o programa "Habitar Brasil" que canalizou recursos orçamentários para financiar a produção de moradias e a urbanização de favelas. No âmbito do programa "Habitar Brasil", foram atendidas cerca de 15 mil famílias em 1993; em 1994, cerca de 35 mil, no âmbito desse e do programa "Morar Pequenas Comunidades" (Souza, 1997).

No governo do presidente Fernando Henrique Cardoso (FHC) foram instituídos e adequados vários programas visando a atender a população de favelas. 0 programa "Habitar Brasil" foi mantido e reestruturado, e foram lançados os Programas de Ação Social e Saneamento (PASS), "Pró-Moradia" e "Pró-Saneamento", os dois últimos utilizando recursos do Fundo de Garantia do Tempo de Serviço (FGTS). Em 1999, no segundo governo de FHC, foi firmado um contrato de empréstimo com o Banco Interamericano de Desenvolvimento (BID) para desenvolvimento do Programa Habitar Brasil/BID (HBB), também voltado para promover a melhoria das condições de habitação em favelas nos moldes do "Habitar Brasil". No entanto, os recursos orçamentários investidos nesse período pós-BNH foram irrisórios. 0 volume dos recursos alocados, assim como a 
regulamentação para sua utilização, não permitiu ampliar a escala de urbanização de favelas no Brasil. ${ }^{3}$

A partir de 2003, início do primeiro governo do presidente Luiz Inácio Lula da Silva, o setor habitacional foi reorganizado institucionalmente e os investimentos na área de habitação foram retomados. 0 investimento em habitação no país cresceu no período compreendido entre os anos de 2003 e 2010, revertendo a estagnação presente no setor desde a extinção do BNH. Os dois principais programas habitacionais lançados pelo governo federal foram o PAC-UAP, em 2007 e o Programa Minha Casa Minha Vida (PMCMV), em 2009.

0 PAC-UAP é voltado para urbanização de favelas e desenvolvido por meio de parceria entre governos estaduais ou municipais, que são os agentes promotores da intervenção, e o governo federal. Financia obras de urbanização (infraestrutura, saneamento, drenagem e contenção geotécnica), equipamentos sociais, produção de novas moradias, requalificação habitacional, trabalho social e regularização fundiária.

Desde 2007, foram contratados R\$33 biIhões em urbanização de favelas, sendo $R \$ 20,8$ bilhões na primeira fase do programa (PAC1), distribuídos em 3.113 empreendimentos, e $\mathrm{R} \$ 12,7$ bilhões na segunda fase do programa (PAC2), correspondendo a 415 empreendimentos e 575 mil famílias beneficiadas (Brasil, 2014, p. 192).

Apesar do investimento significativo, há indícios de que esse programa vem perdendo importância na agenda federal. Um dos motivos seria o baixo índice de execução dos projetos em todo território nacional. Os balanços nacionais dos resultados, produzidos pelo
Ministério das Cidades, em parceria com o Ministério do Planejamento, Orçamento e Gestão, apontam que os resultados projetados em termos de número de obras concluídas, ou em andamento, não foram alcançados. Segundo os dados do $11^{\circ}$ Balanço, até outubro de 2014, apenas $12 \%$ das obras de urbanização da seleção de 2007/2008 foram concluídas e nenhuma obra de urbanização de assentamentos precários da seleção de 2011 foi finalizada.

Segundo Caldas e Vale (2014), até 2014, a média de execução das operações selecionadas no âmbito da carteira do PAC1 (entre 2007 e 2010) era de 65\% e do PAC2 (a partir de 2011) de $5 \%$. Os autores também ressaltam que se deixou de utilizar cerca de $10 \%$ dos recursos disponibilizados.

Como vimos anteriormente, o PAC, desde 2007, selecionou o total de $R \$ 41,5$ biIhões em empreendimentos de urbanização de favelas. Desse total, 1.702 operações, no valor de $\mathrm{R} \$ 4,3$ bilhões, não chegaram a ser contratadas, por deficiência técnica ou documental ou por desistência dos proponentes, ou ainda, tiveram seus contratos cancelados por não iniciarem as obras nos prazos acordados e repetidamente prorrogados ou paralisarem as mesmas por períodos acima dos toleráveis. (Caldas e Vale, 2014)

A baixa execução do programa não deveria representar, entretanto, sua extinção ou diminuição de importância, uma tendência que se observa diante da prioridade dada ao PMCMV, possivelmente em detrimento dos investimentos direcionados a outras modalidades de intervenção como a urbanização de favelas. Grande parcela ${ }^{4}$ da população brasileira vive em favelas e seus assemelhados, e portanto, o tema da urbanização permanece central, e 
o programa federal a ele destinado precisa ser mantido e aprimorado.

Nesse contexto de aumento do investimento federal em projetos de urbanização de favelas, baixa execução dos contratos e limitado conhecimento das possibilidades e dificuldades para ampliar a escala e elevar a qualidade das intervenções em favela, torna-se necessário implementar uma agenda de pesquisa sobre o tema que possa contribuir para o aprimoramento e valorização dessa política pública.

\section{Favelas na Região do ABC: dimensão do problema e intervenção}

\begin{abstract}
A Região do ABC localiza-se no estado de São Paulo, mais precisamente na Região Metropolitana de São Paulo. Segundo dados do Censo Demográfico de 2010, realizado pelo Instituto Brasileiro de Geografia e Estatística (IBGE), residem nessa região 2,5 milhões de habitantes, distribuídos em 865.145 domicílios. Desses domicílios, 115.270 estão localizados em "setores subnormais".
\end{abstract}

Outras fontes de informação, contudo, apresentam números diferentes. Os Planos Locais de Habitação de Interesse Social (PLHIS) da região apontam a existência de 622 assentamentos do tipo favela, que abrigam em torno de 138 mil domicílios.

Muitas favelas da região foram urbanizadas ou parcialmente urbanizadas nos períodos anteriores, porém, nem sempre com a qualidade adequada de intervenção. Em Diadema, $54 \%$ das favelas são consideradas pelo município como "urbanizadas", 39\% receberam algum tipo de melhoria (urbanização parcial) e apenas 7\% não receberam intervenções (Diadema, 2009). Em Santo André, também de acordo com informações municipais, 32\% dos assentamentos são considerados urbanizados (Santo André, 2006) e em São Bernardo do Campo, 37\% (São Bernardo do Campo, 2011).

A maioria dos assentamentos precários localiza-se em áreas com restrição ambiental. Observou-se que $56 \%$ dos assentamentos encontram-se em Área de Preservação Permanente (APP) e 27,82\% em área de proteção e recuperação de mananciais. Estudos revelam, ainda, a existência de um percentual elevado de domicílios em áreas de risco. ${ }^{5}$

$O A B C$ é uma das regiões pioneiras em matéria de urbanização de favelas. Diadema foi uma das primeiras cidades brasileiras a estabelecer, em 1983, uma política abrangente de urbanização de favelas e embora as intervenções nem sempre tenham alcançado um patamar adequado de qualidade, inovou ao tratar a questão da urbanização de favelas não mais como mera intervenção pontual ou programa alternativo. Os Municípios de São Bernardo do Campo e Santo André também iniciaram a implementação de programas de urbanização de favelas no final da década de 1980.

Em São Bernardo do Campo, o primeiro programa de urbanização de favelas foi estruturado em 1989, na primeira gestão do prefeito Maurício Soares. A intervenção em favelas, no âmbito de uma política municipal de habitação em Santo André também foi iniciada no mesmo período. Em 1989, no primeiro governo do prefeito Celso Daniel, foi criado um programa de urbanização de favelas além de terem sido instituídos importantes instrumentos, como 
a Lei de Áreas de Especial Interesse Social (AEIS) e de Concessão de Direito Real de Uso (CDRU). No caso de Diadema, a continuidade político-administrativa propiciada pela eleição consecutiva de três governos progressistas do mesmo partido (Partido dos Trabalhadores), de 1983 a 1996, garantiu que a política para favelas fosse consolidada e aprimorada. Já no caso dos municípios de São Bernardo do Campo e Santo André a alternância política resultou na interrupção do programa e sua posterior retomada.

Denaldi (2003) lembra que a concepção das políticas desenvolvidas nesse período orientava-se para o reconhecimento legal da posse da terra e a garantia de "direitos sociais mínimos", como o acesso ao saneamento. As intervenções realizadas consistiam na abertura de vias e vielas para execução de obras de saneamento e pavimentação. Sempre que possível adotava-se um lote mínimo de 45 a 50 metros quadrados. As obras eram executadas com recursos exclusivamente municipais, uma vez que eram inexistentes ou irrisórios os recursos destinados pelas esferas estadual e federal para intervenções dessa natureza. Ações como produção de novas moradias e requalificação de moradias não eram desenvolvidas. Na década de 1980, a ação municipal caracterizou-se pela intervenção "emergencial", destinada a promover, em algum grau, a melhoria das condições de infraestrutura, com projetos quase sempre executados in loco e que se atinham, na grande maioria dos casos, aos limites do território ocupado pela favela (Denaldi, 2003, p. 191).

No período seguinte (1993-2006), a intervenção foi aprimorada, ingressando na fase de elaboração de projetos de urbanização para a obtenção de recursos e iniciando a intervenção em áreas mais complexas e que demandavam remoções de moradias, portanto, produção de novas unidades habitacionais. Esse período coincidiu com a institucionalização das políticas de urbanização de favelas também no âmbito do governo federal. ${ }^{6}$

0 aprimoramento da intervenção relaciona-se com a valorização do projeto e com a concepção da integração das favelas à cidade. Essa concepção leva os municípios a construírem equipamentos públicos dentro da favela ou no seu entorno imediato, como praças, centros comunitários, centros esportivos, creches e postos de saúde. Nesse período, na região, destacou-se o programa de urbanização de favelas denominado "Santo André Mais Igual", lançado em 1997, que se propunha a articular, institucionalmente, diversos programas setoriais e concentrá-los espacialmente nas favelas em processo de urbanização. Vale pontuar que esse programa ganhou visibilidade nacional e internacional. ${ }^{7}$

A partir de 2007, com o lançamento do PAC-UAP, inaugurou-se um novo período. 0 aumento do volume de recursos federais para urbanização permitiu aumentar a escala de intervenção no âmbito municipal.

A Região do $A B C$ tem 49 assentamentos com algum tipo de intervenção no âmbito do PAC-UAP. Esses assentamentos abrigam cerca de 49 mil famílias, o que corresponde a $40 \%$ do total de famílias que habitam assentamentos precários na região. Desse conjunto de assentamentos, 25 encontram-se no Município de Diadema, 13 em São Bernardo do Campo, nove em Santo André e dois em Mauá. Tais assentamentos abrigam 14.901 famílias residentes no município de Santo André, 15.617 em São 
Figura 1 - Assentamentos com intervenção do PAC-UAP na Região do $A B C$

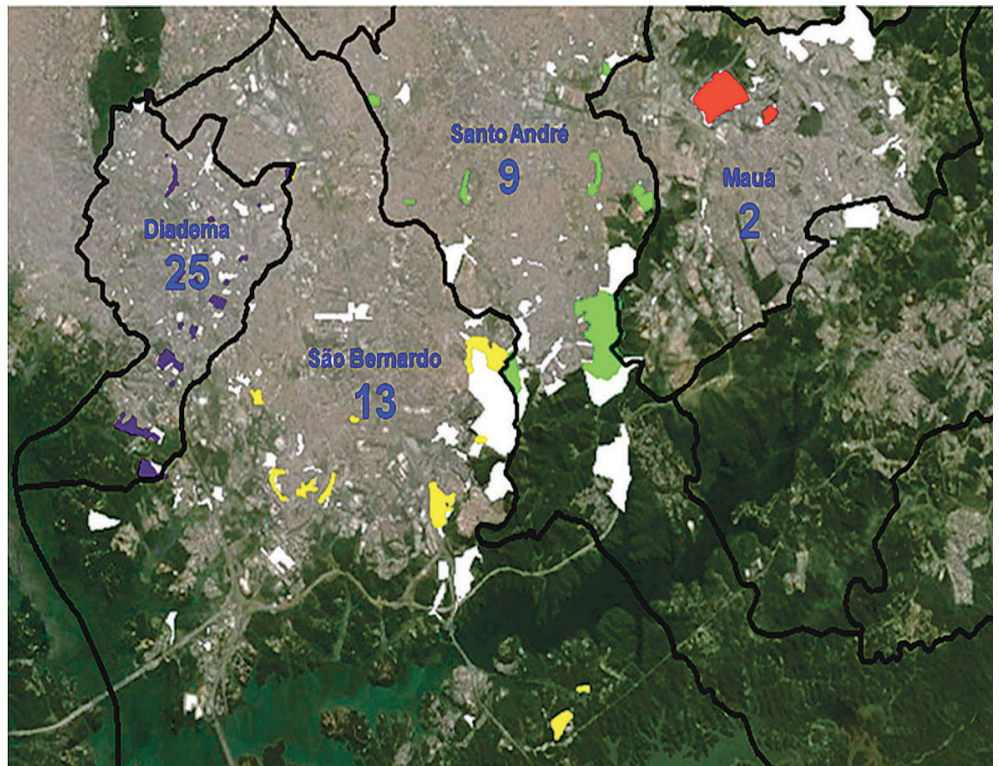

Fonte: IBGE (2010); Moretti et al. (2014).

Nota: as manchas em preto representam os assentamentos precários, segundo o IBGE (2010), e as manchas brancas representam os assentamentos precários com intervenção do PAC-UAP em cada município.

Bernardo do Campo, 10.020 de Diadema e 8.239 de Mauá.

0 investimento total do PAC-UAP na Região do $A B C$ é de 1,3 bilhão de reais e foi viabilizado por meio de 36 operações financeiras firmadas no âmbito do programa. Esse montante não inclui os recursos canalizados para produção habitacional através do Programa Minha Casa Minha Vida (PMCMV), essencial para viabilizar soluções de remanejamento e reassentamento. Desse montante, cerca de $\mathrm{R} \$ 874$ milhões, ou $67 \%$ do total, correspondem a repasses/financiamento do governo federal e $\mathrm{R} \$ 430$ milhões (33\%) a contrapartidas dos governos municipais e estadual. ${ }^{8}$
Desse total de investimentos, mais da metade destinou-se ao Município de São Bernardo do Campo - aproximadamente $\mathrm{R} \$ 685 \mathrm{mi}$ Ihões - seguido pelo Município de Santo André, que conta com o montante de $\mathrm{R} \$ 277$ milhões. Diadema e Mauá contam respectivamente com $\mathrm{R} \$ 162$ e R\$73 milhões em recursos do PAC-UAP. ${ }^{9}$

Os percentuais de contrapartida diferem muito entre os municípios, variando de $5 \%$, no caso de Mauá, a $41 \%$, no caso de São Bernardo do Campo, que apresenta valores de contrapartida que se aproximam aos de repasse/financiamento.

Os recursos do PAC-UAP chegaram à região, até dezembro de 2013, por meio de 36 
Termos de Compromisso (TC). ${ }^{10}$ Os TC podem canalizar recursos para mais que um assentamento, da mesma forma que um único assentamento pode receber recursos por meio de dois ou mais TC. Portanto, não necessariamente um TC canaliza recursos para promover a urbanização completa de um único assentamento ou complexo, podem canalizar recursos para um setor do assentamento, tipo de problema ou etapa da obra de urbanização.

Observa-se que a intervenção em favelas na região ganhou escala com o lançamento do PAC-UAP; entretanto, seguindo a tendência nacional, é baixa a execução do programa na região. Na Região do $\mathrm{ABC}$, a exemplo do que se observa no cenário nacional, também tem sido baixa a execução do programa. Do total de operações contratadas, até setembro de 2013, quase $30 \%$ ainda não tinham sido iniciados e apenas $6 \%$ estavam concluídos, ou seja, apenas duas das 36 operações contratadas foram finalizadas até aquele momento (período de sete anos de vigência do PAC-UAP). ${ }^{11}$

\section{Características dos assentamentos e investimentos do PAC-UAP}

No âmbito da pesquisa "Urbanização de Assentamentos precários no âmbito do Programa de Aceleração do Crescimento na Região do $A B C$ ", financiada pelo Conselho Nacional de Desenvolvimento Científico e Tecnológico (CNPq) - Chamada MCTI/CNPq/MCidades $n^{\circ}$ 11/2012 -, foram caracterizadas as intervenções de urbanização de favelas, em execução ou programadas, na Região do $A B C$ e para as quais se destinam recursos do PAC-UAP.
A maioria dos assentamentos que recebem investimentos do PAC-UAP na região apresenta densidades entre 500-1000 habitantes por hectare (hab/ha), existindo uma variação de densidade muito grande: de 89 hab/ha a 1.127 hab/ha (ambos localizados no Município de Diadema). 0 porte dos assentamentos também é muito variado (número de famílias consideradas nos projetos de urbanização): dois assentamentos abrigam mais que 5.000 famílias, nove assentamentos contam com um número de famílias entre 1.001 e 5.000 e 25 com menos de 500 famílias envolvidas.

Observou-se que $45 \%$ dos assentamentos da região estão localizados em terrenos com predomínio de relevo acidentado e $17 \%$ com presença significativa de relevo acidentado, demandando intervenções de estabilização geotécnica. Foram também investigados os gravames ambientais incidentes sobre os assentamentos com intervenção do PAC na Região do $A B C$. No conjunto dos assentamentos estudados, existem 16 assentamentos localizados em Área de Proteção e Recuperação de Mananciais (APRM) da Represa Billings. Vinte e cinco assentamentos (51\%) desse conjunto apresentam gravames relacionados a Áreas de Preservação Permanente (APP) de cursos d'água. Quatorze assentamentos, dentre os 49 estudados (29\%), apresentam gravames relacionados a APP de nascente.

No conjunto estudado, somente em nove assentamentos não foram identificadas situações de risco nas condições pré-intervenção. Risco associado a deslizamentos é o mais expressivo, presente em $55 \%$ das favelas estudadas. Também foram citados riscos de inundação (em 37\% dos assentamentos) e de solapamento ou erosão de margens de córregos (em 
39\%). Observa-se que, em muitos dos assentamentos, há incidência de mais de um processo geodinâmico gerador de riscos.

Identificou-se que a maioria dos assentamentos beneficiados pelo programa PAC-UAP já recebeu algum tipo intervenção de urbanização em períodos anteriores. De acordo com informações municipais, dos 49 assentamentos que contam com recursos do PAC-UAP, 39 deles $(80 \%)$ receberam intervenções realizadas com recursos de outras fontes nas últimas três décadas. A informação sobre a infraestrutura existente antes da intervenção do PAC-UAP confirma essa informação. Os municípios declararam que $92 \%$ dos assentamentos tinham redes de água, integral ou parcial, antes da intervenção; $85 \%$ de esgoto e $90 \%$ de drenagem. ${ }^{12}$

As intervenções foram classificadas em seis tipos como mostra a Tabela 1. Conclui-se que $27 \%$ das intervenções são do tipo urbanização com construção de novas unidades habitacionais no próprio assentamento (remanejamento), 22\% são do tipo urbanização com construção de novas unidades habitacionais tanto no próprio assentamento (remanejamento) como fora dele (reassentamento) e $22 \%$ do tipo urbanização com produção de novas moradias fora do assentamento (reassentamento). A substituição total das moradias do assentamento por unidades habitacionais ${ }^{13}$ (UHs) novas foi registrada em apenas sete assentamentos (14\%) e a remoção total do núcleo e reassentamento da população em outro local em apenas quatro assentamentos (8\%).

Segundo informações municipais, muitos assentamentos já haviam sido parcialmente "urbanizados", ou seja, receberam algum tipo de melhoria em períodos anteriores. Desse conjunto de 49 assentamentos precários objeto de intervenção no âmbito do PAC-UAP, mais da metade $(53 \%)$ das intervenções representam complementação de urbanização. Quase metade $(43 \%)$ tem por objetivo a urbanização completa dos assentamentos precários e apenas $4 \%$ pretendem urbanizar apenas um setor do assentamento. Destaca-se que, no caso de Diadema,

Tabela 1 - Tipo de intervenção no âmbito do PAC-UAP na Região do ABC

\begin{tabular}{l|c|c}
\hline \multicolumn{1}{c|}{ Tipo de intervenção } & $\begin{array}{c}\text { No de } \\
\text { assentamentos }\end{array}$ & $\%$ \\
\hline Urbanização com consolidação das famílias na própria área (sem realocação) & 3 & 6 \\
Urbanização com construção de UHs no próprio assentamento & 13 & 27 \\
$\begin{array}{l}\text { Urbanização com construção de UHs no próprio assentamento e com reassentamento } \\
\text { de parte da população removida em outro local }\end{array}$ & 11 & 22 \\
Urbanização com reassentamento externo da população & 11 & 14 \\
Substituição total das moradias do assentamento por UHs novas & 7 & 8 \\
Remoção total do núcleo e reassentamento da população em outro local & 4 & 100 \\
\hline Total ABC & 49 & 22 \\
\hline
\end{tabular}

Fonte: Moretti et al. (2014). 
a intervenção em 18 assentamentos (72\% do total do município) é do tipo complementação da urbanização e, nos casos de São Bernardo e Santo André, predomina a intervenção do tipo urbanização completa. A eliminação de riscos é elemento indutor da urbanização.

Comparando o número de unidades habitacionais em risco antes e depois de iniciadas as intervenções, observa-se redução de quase 75\% em São Bernardo do Campo, Mauá e Diadema e quase $80 \%$ em Santo André. Estima-se que, com a conclusão das obras, se alcance a redução de $100 \%$.

Além dos recursos captados no âmbito das modalidades do PAC-UAP e vinculados aos 36 TC, foram e estão sendo viabilizados recursos no âmbito do Programa Minha Casa Minha Vida (PMCMV) para viabilizar soluções de remoção (remanejamento ou reassentamento). Até dezembro de 2013, foi contratada a construção de quatro conjuntos habitacionais por meio do PMCMV vinculado às urbanizações do PAC-UAP no ABC, totalizando 1.652 UH e aproximadamente R\$107 milhões de investimento, de acordo com as informações fornecidas pelos municípios.

Entretanto, a quantidade de novas moradias contratadas no âmbito do PMCMV, até dezembro de 2013, não era suficiente para atender ao universo de famílias que precisavam ser removidas e reassentadas no âmbito do PAC-UAP. Os municípios estavam articulando novas propostas no âmbito do PMCMV para concluir o processo de urbanização. Segundo informações municipais, existem cerca de dez projetos de conjuntos habitacionais em elaboração ou processo de aprovação para captação de recursos no âmbito do PMCMV e que viabilizam a construção de cerca de 2.500 novas moradias.

Tabela 2 - Unidades habitacionais por tipologia de risco nos municípios do $A B C$ antes e depois da intervenção do PAC-UAP

\begin{tabular}{l|c|c|c|c|c|c|c|c}
\hline \multicolumn{1}{c|}{ Município } & \multicolumn{2}{c|}{ SA } & \multicolumn{2}{c|}{ ABC } & \multicolumn{2}{c}{ Diadema } & \multicolumn{2}{c}{ Mauá } \\
\hline \multicolumn{1}{c|}{$\mathbf{N}^{\circ}$ de UHs } & $\begin{array}{c}\text { Antes da } \\
\text { intervenção }\end{array}$ & Atual & $\begin{array}{c}\text { Antes da } \\
\text { intervenção }\end{array}$ & Atual & $\begin{array}{c}\text { Antes da } \\
\text { intervenção }\end{array}$ & Atual & $\begin{array}{c}\text { Antes da } \\
\text { intervenção }\end{array}$ & Atual \\
\hline Inundação & 30 & - & 1.413 & 186 & 972 & 149 & - & - \\
Deslizamento & 1.900 & 481 & 983 & 426 & 611 & 192 & 1.218 & 304 \\
Solapamento & 1.300 & - & 334 & 66 & 78 & 21 & - & - \\
Outros & 1.185 & 420 & 121 & 67 & - & 24 & - & - \\
\hline $\begin{array}{l}\text { Total de UHs } \\
\text { em risco }\end{array}$ & 4.415 & 901 & 2.851 & 745 & 1.661 & 386 & 1.218 & 304 \\
\hline
\end{tabular}

Fonte: Moretti et al. (2014). 
Tabela 3 - Recursos contratados e previstos para viabilizar a urbanização dos assentamentos no âmbito do PAC-UAP

\begin{tabular}{l|c|c|c}
\hline \multicolumn{1}{c|}{ Município } & PAC-UAP - R\$ & $\begin{array}{c}\text { PAC-UAP + } \\
\text { PMCMV contratado }\end{array}$ & $\begin{array}{c}\text { PAC-UAP + PMCMV } \\
\text { contratado e previsto* }\end{array}$ \\
\hline Santo André & $384.934 .543,31$ & $460.404 .756,49$ & $460.404 .756,49$ \\
São Bernardo do Campo & $684.740 .634,21$ & $716.659 .226,37$ & $763.123 .226,37$ \\
Diadema & $161.653 .694,61$ & $161.653 .694,61$ & $267.733 .694,61$ \\
Mauá & $72.531 .819,27$ & $72.531 .819,27$ & $150.483 .819,27$ \\
\hline Total & $1.303 .860 .691,40$ & $1.411 .249 .496,74$ & $1.641 .745 .496,74$ \\
\hline
\end{tabular}

* a estimativa prevista de investimento do PMCMV foi calculada a partir do número de UHs necessárias para conclusão da urbanização, informada pelas prefeituras, multiplicada pelo valor do teto do programa na RMSP (R \$96mil).

Fonte: MCidades e entrevista com técnicos das Prefeituras Municipais.

0 custo total de investimento por família no âmbito das contratações do PAC-UAP não representa o custo total (realizado ou necessário) de investimento para concluir a intervenção de urbanização, incluindo as ações de produção de moradias para reassentamento. Como mencionado anteriormente, o recurso captado no âmbito do programa, em muitos casos, é insuficiente para concluir todas as obras de urbanização e viabilizar os reassentamentos. Além disso, a maioria dessas áreas foi urbanizada parcialmente ou recebeu algum tipo de melhoria em períodos anteriores. Essas melhorias foram executadas com recursos próprios do Estado e Municípios ou recursos federais captados no âmbito de programas, dentre outros, como o "Habitar Brasil/BID".

A média do investimento por família no âmbito das contratações do PAC-UAP na região é de $R \$ 27 m i l$, e essa varia de $R \$ 9$ mil reais por família, no caso de Mauá, a R\$44 mil por família, em São Bernardo do Campo. ${ }^{14}$ Quando a análise é feita por assentamento, e não por município, observam-se variações ainda maiores - de R $\$ 4$ mil a $\mathrm{R} \$ 90 \mathrm{mil}^{15}$ mas esses dados devem ser lidos com cautela.

Em alguns casos, esse valor é baixo devido ao fato de o investimento total do PAC-UAP considerado corresponder a intervenções em apenas parte da área e o número de famílias corresponder ao total do assentamento. Esse é o caso do Núcleo Nova Conquista, em Diadema, que apresenta o menor valor de investimento por família ( $\mathrm{R} \$ 4 \mathrm{mil}$ ): o núcleo abriga 2.300 famílias, mas o setor atendido pelo PAC-UAP corresponde apenas a um setor conhecido como "Setor Krones". O restante do assentamento foi urbanizado anteriormente, com recursos provenientes de outras fontes. Caso semelhante pode ser verificado no Núcleo Sacadura Cabral, em Santo André, que conta com investimento de aproximadamente R\$ 4.600 por família, contudo, trata-se de um pequeno setor da favela que já foi urbanizada na década de 2000 com recursos municipais, federais e da União Europeia. No caso do 
núcleo que conta com o maior valor de investimento por família ( $\mathrm{R} \$ 90 \mathrm{mil}$ ). No caso do Silvina Oleoduto (localizado em São Bernardo do Campo), a presença de um oleoduto impõe a remoção de grande parcela das famílias e eleva o custo de intervenção.

Os referidos valores de investimento por família elevam-se quando somados aos recursos contratados e planejados (previsão) no âmbito do PMCMV. Considerando a viabilização da captação de recursos para construção das unidades habitacionais necessárias, 0 investimento médio por família na região subirá para $\mathrm{R} \$ 33.658$, com variação por município de $\mathbf{R} \$ 18.265$ por família, no caso de Mauá, e R\$ 48.865 por família, no caso de São Bernardo do Campo.

\section{0 que explicaria 0 baixo desempenho do programa?}

A análise das características dos assentamentos e intervenções realizadas no âmbito do PAC-UAP na região permite apontar um conjunto de fatores que explicariam o baixo desempenho do programa na região.
Observando o panorama geral apresentado, o primeiro ponto a ser destacado é que a característica física dos assentamentos localizados na Região do $A B C$ são aquelas descritas para as regiões metropolitanas e indicam a complexidade de intervenção nesses territórios. A maioria dos assentamentos está localizada em áreas com presença de gravames ambientais, relevo acidentado e situações de risco. Soma-se isso ao fato de os assentamentos encontrarem-se consolidados, com alta densidade e setores urbanizados em períodos anteriores com qualidade inadequada. Essa característica indica a complexidade da intervenção física e do trabalho social. Apontando, dessa forma, a necessidade de realização de diagnósticos integrados, obtenção de autorização ou licenciamento ambiental e execução de complexas obras de saneamento, drenagem e consolidação geotécnica. Isso, muitas vezes, implica intervir na escala do entorno ou microbacia. Além disso, quase sempre requer a remoção de percentual significativo da população residente para viabilizar obras de infraestrutura e eliminação de situações de risco.

Evidentemente, a intervenção numa área desse tipo é mais complexa do que a

Tabela 4 - Investimento médio por família de acordo com as fontes de financiamento e situação de contratação ou previsão

\begin{tabular}{l|c|c|c}
\hline \multicolumn{1}{c|}{ Município } & $\begin{array}{c}\text { PAC-UAP Total } \\
\text { R\$ }\end{array}$ & $\begin{array}{c}\text { PAC-UAP + MCMV } \\
\text { contratado - R\$ }\end{array}$ & $\begin{array}{c}\text { PAC-UAP + PMCMV } \\
\text { (previsão) - R\$ }\end{array}$ \\
\hline Santo André & 25.833 & 30.898 & 30.898 \\
São Bernardo do Campo & 43.846 & 45.890 & 48.865 \\
Diadema & 16.133 & 16.133 & 26.720 \\
Mauá & 8.805 & 8.805 & 18.265 \\
\hline Região & 26.732 & 28.933 & 33.658 \\
\hline
\end{tabular}

Fonte: Moretti et al. (2014). 
intervenção que se realiza numa área vazia (desocupada). Ainda que o município contasse com um projeto executivo completo e de bom nível, - o que não tem sido observado, - seria de difícil execução em curto prazo, tendo em vista essa complexidade física e social.

Os projetos produzidos nem sempre estão baseados em diagnósticos integrados, quase nunca estão completos e têm um grau insuficiente de detalhamento. ${ }^{16}$ Esse fato aumenta a imprevisibilidade já existente em projetos dessa natureza e provoca a necessidade de produção ou alteração de projetos e de revisão de planilhas (quantitativos e orçamento) durante a execução da obra, levando frequentemente a sua paralisação temporária. Vários autores ${ }^{17}$ apontam que apenas na década de 1990 o projeto de urbanização de favelas foi valorizado. Nesse período, foram formuladas diretrizes de intervenção que consideravam a necessidade de integração do assentamento à cidade e fossem definidos padrões específicos de execução de obras. Ainda há limitado acúmulo no campo da elaboração de projeto e obra para favela.

Outro aspecto a ser considerado é que se trata de um território em permanente transformação pela ação de seus moradores ou do meio físico. É comum que uma obra se inicie apenas dois anos depois de concluída a elaboração do projeto ou três anos após a conclusão de seu diagnóstico integrado. Após a conclusão da elaboração do projeto, é preciso muitas vezes obter a autorização ambiental para só então apresentá-lo para avaliação da Caixa Econômica Federal (CEF), ou órgão financiador, para depois formalizar a contratação e iniciar o processo de licitação. Esses procedimentos de licenciamento, avaliação, contratação e licitação são morosos. Também é comum que, nesse período, alterem-se as condições de ocupação e características do sítio. Mesmo contando com um projeto de boa qualidade, muitas vezes, é necessário produzir revisões e complementações que alteram o escopo original. A lógica de projeto, financiamento e controle da execução das obras de urbanização de favelas segue aquela que é adotada na implantação de uma obra nova, em que o território ainda não foi ocupado. Porém, tem-se na prática uma intervenção que mais se assemelha a uma obra de reforma, onde a intervenção ocorre em uma situação já existente e em mutação. Considera-se importante e oportuno o debate sobre novas formas de projetar, orçar e reembolsar as obras de urbanização de assentamentos precários, considerando essa especificidade.

Soma-se a essa combinação "complexidade de intervenção, qualidade do projeto e território em transformação", a rigidez de contratação e medição das obras de urbanização de favelas apontadas pelos técnicos e gestores municipais. ${ }^{18} \mathrm{~A}$ rigidez das normas de contratação e medição não é compatível com a característica do projeto, território e complexidade de intervenção.

Outro tema a ser explorado relaciona-se com a natureza da intervenção, custos de urbanização e desenho do PAC-UAP. As propostas para produção de novas moradias no âmbito do PMCMV, atreladas às urbanizações desse conjunto de assentamentos estudados, comprovam o fato. Os municípios informaram que estão sendo pleiteados recursos adicionais do PMCMV para concluir a urbanização de $22 \%$ dos assentamentos analisados, apontando a necessidade de construção de no mínimo mais 2.500 moradias, envolvendo recursos da ordem de $\mathrm{R} \$ 230$ milhões. Em alguns casos, como o 
Jardim Oratório, em Mauá, faltam recursos tanto para construção de novas moradias, como para resolver as situações mais complexas de risco e infraestrutura, como miolos de quadra e topos de morro.

Conclui-se que a urbanização de grande parcela desses assentamentos foi iniciada em períodos anteriores e que o valor destinado e contratado, embora expressivo, não será suficiente para concluir a intervenção. Esse fato pode corroborar com a morosidade da execução dos contratos, uma vez que para realizar alguns tipos de serviços (tais como abertura de viário, canalização e recuperação de córrego, recuperação de área de risco) é necessária a provisão de moradias para viabilizar a remoção. Portanto, a ausência de projeto e financiamento integrado para todos os componentes da intervenção pode comprometer a execução das obras contratadas.

Por fim, a lógica do projeto apresentado, o volume de recurso solicitado para o Ministério das Cidades e os limites de financiamento por componente do programa podem dificultar ou impossibilitar a conclusão da urbanização. Observa-se, como no caso do Jardim Oratório, o estudo de caso da segunda etapa dessa pesquisa, que muitas vezes os municípios tentam encaixar em "determinado valor captado" alguns serviços e obras necessárias, mas que esse montante é insuficiente para conclusão da obra. Nos casos em que se observa a dificuldade ou impossibilidade de captação de recursos para produção habitacional, executa-se o que é possível sem a remoção da população ou com a remoção parcial. Essa "conta de chegada" acaba comprometendo a qualidade da intervenção. Observa-se que essa prática se relaciona tanto com a inexistência de projetos completos e de boa qualidade, portanto, com a limitada capacidade administrativa do município, como com as regras e limites de financiamento do programa.

Os custos de urbanização por família e limites de investimento por item do programa também podem dificultar a execução de soluções adequadas e tornar ainda mais morosa a execução das obras de urbanização, principalmente nos casos de intervenções executadas na primeira fase do programa. As características físicas e de ocupação dos assentamentos são muito distintas, e em muitos casos a intervenção é complexa, e pode custar mais que os limites de repasse por família estabelecidos pelo programa. Novamente, nesse caso muitas vezes o município faz uma conta de chegada e não contrata a execução de todos os serviços e obras necessários. A orientação operacional $n^{\circ}$ 01/2011 do Ministério das Cidades, instituído em 22 de fevereiro de 2011, exclui do enquadramento itens muito variáveis como obras para eliminação de risco, o que significa que não são estabelecidos limites de investimento para tais itens, além de possibilitar requisição de recurso adicional para construção de unidades habitacionais executadas no âmbito do PMCMV, entretanto, há indícios que, em alguns casos, ainda assim os limites estabelecidos pelo programa não são suficientes para executar a intervenção como um todo. Para "fechar a conta", o município aumenta sua contrapartida ou exclui serviços. Muitas vezes a execução das obras fica comprometida porque o município não consegue cumprir a contrapartida ou a exclusão dos serviços compromete a execução de outros. 


\section{Conclusão}

A primeira constatação é que os recursos do PAC-UAP permitiram ampliar significativamente a escala de intervenção em favelas na Região do ABC. Conclui-se que cerca de $40 \%$ dos domicílios em assentamentos precários estão localizados em assentamentos que recebem algum tipo de intervenção no âmbito do PAC-UAP. ${ }^{19}$ Em que pese o fato de a urbanização da maioria desses assentamentos ter sido iniciada em períodos anteriores e os investimentos alocados muitas vezes serem ainda insuficientes para concluir a urbanização e integração do assentamento na cidade, trata-se de uma intervenção de grande abrangência em termos do número de assentamentos beneficiados. Vale ressaltar que as intervenções do tipo urbanização de favelas na Região do $A B C$ foram iniciadas na década de 1980 e, mesmo com as interrupções decorrentes das alternâncias de governo, foram mais de 30 anos de práticas de urbanização de favelas antes do lançamento do PAC em 2007 e apenas cerca de $20 \%$ dos domicílios estão localizados em assentamentos integralmente urbanizados no período anterior. ${ }^{20}$ Portanto, as intervenções realizadas no âmbito do PAC terão um significativo impacto na região.

Uma segunda constatação é que, mesmo antes do término das obras, as intervenções já obtiveram significativo resultado na redução de riscos e recuperação ambiental dos assentamentos, em especial aqueles relacionados aos aspectos de drenagem e recuperação da margem dos cursos d'água.
Entretanto, conforme mencionado anteriormente, apenas $6 \%$ das obras estão concluídas e a média de execução do PAC1 é de 54\% e do PAC2 3\%.

Conclui-se que, para compreender os baixos índices de execução das obras de urbanização de favelas nessa região e no Brasil, será importante entender a característica desses assentamentos, a natureza dessas intervenções, as limitações institucionais dos governos municipais e da CEF, além de identificar os obstáculos colocados pela regulamentação do programa e forma de contratação e gestão dos projetos por parte do governo federal (MCidades e CEF).

As informações produzidas no âmbito desse trabalho são insuficientes para tecer conclusões sobre o baixo índice de execução das obras, mas permitem apontar alguns fatores que podem contribuir para explicar esse desempenho do programa. Dessa forma, buscou-se indicar hipóteses que deverão ser confirmadas por outros estudos.

0 tema do custo de urbanização por família em Regiões Metropolitanas (RM) também merece ser estudado. 0 panorama dos investimentos realizados mostrou que há uma grande variação de custo de investimento por família e por empreendimento. Evidentemente, em cada caso, a natureza da intervenção, existência de gravames ambientais, estágio de urbanização, qualidade e partido do projeto justificam, em grande parte, essa variação. Na região do $A B C$, onde predominam casos complexos, os custos de urbanização tendem a ser superiores aos limites estabelecidos pelo programa. Cabe destacar que a urbanização de favelas envolve 
uma análise de custos mais abrangente do que a das obras de consolidação urbanística. A rede de proteção e o capital social constituído em um núcleo de assentamento informal é difícil de ser computado, mas não pode ser ignorado. Porém, é importante reconhecer a tendência de aumento dos custos de urbanização de assentamentos informais nos últimos anos. Esse aumento está associado a um conjunto de fatores, entre os quais o aumento do percentual de famílias removidas para atendimento às exigências de proteção ambiental, e a adoção de estratégias de intervenção que demandam a incorporação de diferentes componentes além da execução de obras complexas que extrapolam os limites da favela.

\section{Rosana Denaldi}

Universidade Federal do ABC, Centro de Engenharia, Modelagem e Ciências Sociais Aplicadas. Santo André/SP, Brasil.

denaldi.rosana@gmail.com

\section{Ricardo Moretti}

Universidade Federal do ABC, Centro de Engenharia, Modelagem e Ciências Sociais Aplicadas. Santo André/SP, Brasil.

ricardo.moretti@ufabc.edu.br

\section{Claudia Paiva}

Universidade Federal do ABC, Centro de Engenharia, Modelagem e Ciências Sociais Aplicadas. Santo André/SP, Brasil.

claudia.paiva@ufabc.edu.br

\section{Fernando Nogueira}

Universidade Federal do ABC, Centro de Engenharia, Modelagem e Ciências Sociais Aplicadas. Santo André/SP, Brasil.

fernandorochanogueira2808@gmail.com

\section{Juliana Petrarolli}

Universidade Federal do ABC, Programa de Pós Graduação em Planejamento e Gestão do Território. Santo André/SP, Brasil.

ju.petrarolli@gmail.com 


\section{Notas}

(1) Apresenta os resultados da pesquisa "Urbanização de assentamentos precários no âmbito do Programa de Aceleração do Crescimento na Região do ABC", produzida pelos autores e financiada pelo Conselho Nacional de Desenvolvimento Científico e Tecnológico (CNPq) Chamada MCTI/CNPq/MCidades no 11.

(2) Utilizaremos a sigla "PAC-UAP" para tratar das operações de financiamento e repasse de recursos do Governo Federal no âmbito do PAC, que tem como finalidade promover obras de urbanização de assentamentos precários.

(3) Segundo balanço divulgado pelo governo federal, em 1999, o investimento realizado no período de 1995 a 1999, foi de $R \$ 773$ milhões no programa Pró-Moradia, de $R \$ 2,664$ milhões no Pró-Saneamento, de $\mathbf{R} \$ 695,1$ milhões no Habitar Brasil e de $\mathrm{R} \$ 803$ milhões no PASS (Brasil, 1999, apud Denaldi, 2003, p. 24).

(4) Segundo IBGE (1996), em 2010 existiam 11,4 milhões de pessoas vivendo em aglomerados subnormais no Brasil. Maricato (1996) estima que de $40 \%$ a $50 \%$ da população das grandes cidades brasileiras vive na informalidade, sendo $20 \%$ em favelas.

(5) Em mapeamentos realizados entre 2009 e 2013 em assentamentos precários de seis dos sete municípios da região, foram identificadas mais de 24 mil moradias em situação de risco associados a deslizamentos, solapamento de margens de córregos e inundações, das quais 9.374 estavam em risco alto ou muito alto.

(6) Sobre a evolução da política de urbanização de favelas, ver Denaldi (2003) e Cardoso (2006).

(7) Principais premiações: "Prêmio Gestão Pública e Cidadania" concedido pelas Fundações Getúlio Vargas e Ford, em 2000; eleita uma das 16 melhores práticas do mundo, escolhidas para serem relatadas na Conferência das Nações Unidas sobre Assentamentos Humanos - Istambul + 5 em 2001; Prêmio Internacional de Dubai de Melhores Práticas, do Centro das Nações Unidas para Assentamentos Humanos, o Habitat, em 2002. Ver Denaldi (2012).

(8) Na Região do $A B C$, no âmbito do PAC-UAP, o governo federal aporta cerca de $R \$ 873$ milhões no Programa, os municípios, $\mathrm{R} \$ 360$ milhões, e o governo estadual, $\mathrm{R} \$ 70$ milhões.

(9) Após a conclusão da primeira etapa da pesquisa, tomou-se conhecimento que o Núcleo Vila Ferreira, localizado no Município de São Bernardo do Campo, também conta com recursos do PAC-UAP. Esse relatório não incorpora as informações sobre esse assentamento.

(10) O PAC-UAP tem Subprogramas e Ações em que se categorizam as intervenções, são elas: Projetos Prioritários de Investimentos - Intervenções em Favelas (PPI-IF), Projetos Prioritários de Investimentos - Saneamento Integrado (PPI-SI), Fundo Nacional de Habitação de Interesse Social (FNHIS), ProMoradia e PAC-Risco. Segundo pesquisa feita com os agentes promotores das intervenções,15 TC estavam inseridos na Ação PPI-IF, nove no FNHIS, cinco no PPI-Saneamento Integrado, três no ProMoradia, dois são do PAC-Risco e dois termos não temos informação a esse respeito.

(11) Os dos Termos de Compromisso concluídos até setembro de 2013 inserem-se no município e São Bernardo do Campo. São eles TC. 233.651-94/2007, para urbanização do Núcleo Vila Esperança e o TC. 229.052-61/2009, que tinha como objeto a construção do Conjunto Habitacional Três Marias e a urbanização dos núcleos Sítio Bom Jesus/Alvarenga Peixoto, Divineia Pantanal e Jardim Ipê. 
(12) Em alguns casos, essas redes foram ou estão sendo refeitas em razão de haver interferência com outras obras ou para melhorar a qualidade da prestação dos serviços.

(13) São muito peculiares as situações de substituição total de moradias existentes novas. Esse tipo de intervenção foi observado apenas nos municípios de São Bernardo do Campo e em Diadema. No caso dos assentamentos denominados Pau do Café em Diadema e Jardim Esmeralda em São Bernardo do Campo, as habitações existentes eram muito precárias. No caso do núcleo Jóquei, em Diadema, tratava-se de uma pequena área de risco localizada em um complexo de favelas, e o recurso do PAC foi destinado apenas para remoção das famílias dessa área que foram levadas para um conjunto habitacional localizado no complexo que teve a maior parte de sua área consolidada. A situação mais singular talvez seja a do assentamento Silvina Oleoduto no município de São Bernardo do Campo. A favela localizava-se entre a rodovia Anchieta e o Oleoduto da Transpetro, configurando-se também como área de risco. A solução encontrada foi remover as famílias para conjunto habitacional localizado no entorno.

(14) São aqui considerados o valor total de investimento dos Termos de Compromisso do PAC-UAP no $A B C$, dividido pelo número total de moradores dos assentamentos beneficiados pelo programa, fornecidos pelas Prefeituras e CDHU.

(15) Valores aproximados.

(16) Afirmação baseada nos resultados da pesquisa "Urbanização de Assentamentos precários no âmbito do Programa de Aceleração do Crescimento na Região do ABC".

(17) Ver Bueno (2000); Denaldi (2003); Moretti et al. (2009).

(18) Informações fornecidas na oficina realizada em 10 de setembro de 2013, na UFABC - Campus de Santo André, para apresentar e debater os primeiros resultados na visão panorâmica dos empreendimentos do PAC-UAP na Região do ABC. Participaram dessa oficina os representantes dos municípios estudados, Caixa Econômica Federal e Companhia de Desenvolvimento Habitacional e Urbano.

(19) De acordo com o IBGE (2010), a Região do ABC tem cerca de 115 mil domicílios em assentamentos precários (setores subnormais) e, de acordo com informações municipais registradas nos PLHIS, 211 mil domicílios, e cerca de 138 mil são assentamentos "irregulares e precários" e 73 mil apenas "irregulares".

(20) A informação produzida tem como fonte os PLHIS elaborados pelos municípios de São Bernardo do Campo (2010), Santo André (2006; 2011), Mauá (2011) e Diadema (2009) elaborados em diferentes períodos. $\mathrm{O}$ dado pode estar subestimado.

\section{Referências}

BRASIL. (2014). Comitê Gestor do PAC. $11^{\circ}$ Balanço do PAC2 - set/dez. Disponível em: http://www.pac. gov.br/pub/up/pac/11/PAC11_MinhaCasaMinhaVida.pdf. Acesso em: 10 jun 2015.

BUENO, L. M. (2000). Projeto e favela: metodologia para projetos de urbanização de favela. Tese de doutorado. São Paulo, Universidade de São Paulo. 
CALDAS, M. F. e VALE, M. L. (2014). O programa de aceleração do crescimento e as obras de infraestrutura urbana - avanços e desafios. In: I URBFAVELAS - Seminário Nacional sobre Urbanização de Favelas. Anais. São Bernardo do Campo, UFABC.

CARDOSO, A. (2007). Avanços e desafios na experiência brasileira de urbanização de favelas. Cadernos Metrópoles. São Paulo, v. 9, n. 17. pp. 219-240.

DENALDI, R. (2003). Políticas de urbanização de favelas: evolução e impasses. Tese de doutorado. São Paulo, Universidade de São Paulo. (2004). Estado, políticas habitacionais e favelas no Brasil. Revista Leopoldianum. Santos - SP, v. 81-82, pp. 65-90.

(2012). “Urbanização de favelas no âmbito do Programa Santo André Mais Igual”. In: DENALDI, R. (org.) O desafio de planejar a cidade. Política Habitacional e Urbana de Santo André/SP (19972008). São Paulo, Annablume.

DIADEMA (2009). Plano Local de Habitação de Interesse Social de Diadema. Diadema, Prefeitura do Município de Diadema.

MAGALHÃES, I. (2013). "Planos Locais de Habitação na estratégia da Política Nacional de Habitação". In: DENALDI, R. (org.). Planejamento Habitacional: notas sobre precariedade e terra nos Planos Locais de Habitação. São Paulo, Annablume.

MARICATO, E. (1996). Metrópole da periferia do capitalismo. llegalidade, desigualdade e violência. São Paulo, Hucitec.

MAUÁ (2011). Plano Local de Habitação de Interesse Social de Mauá. Mauá, Prefeitura do Município de Mauá.

MORETTI, R. S.; COMARU, F. e SAMORA, P. R. (2009) "Definição das diretrizes de intervenção operacionalização das intervenções integradas em assentamentos precários". In: DENALDI, R. (org.). Ações integradas de urbanização de assentamentos precários. Brasília/São Paulo, Ministério das Cidades/Aliança de Cidades, v. 1, pp. 203-234.

MORETTI, R. S. et al. (2014). Identificação e caracterização dos empreendimentos do PAC-UAP na Região do $A B C$. Relatório de pesquisa. Santo André, UFABC.

SANTO ANDRÉ (2006) Plano Local de Habitação de Interesse Social de Santo André. Santo André, Prefeitura do Município de Santo André.

SÃO BERNARDO DO CAMPO (2011). Plano Local de Habitação de Interesse Social de São Bernardo do Campo. São Bernardo do Campo, Prefeitura Municipal de São Bernardo do Campo.

SOUZA, M. T. X. (1997). Relatório de Política Habitacional 1991-1996. Campinas, NEPP/Unicamp.

Texto recebido em 12/jun/2015

Texto aprovado em 7/nov/2015 